This article is licensed under the Creative Commons Attribution-NonCommercial 4.0 International License (CC BY-NC) (http://www.karger.com/Services/OpenAccessLicense). Usage and distribution for commercial purposes requires written permission.

\title{
Intraparenchymal Hemorrhage due to Brain Metastasis of Hepatocellular Carcinoma
}

\author{
Rafael Sartori Balbinot ${ }^{a} \quad$ Ana Laura Facco Muscope ${ }^{a} \quad$ Mateus Dal Castel $^{\mathrm{a}}$ \\ Silvana Sartori Balbinot ${ }^{a, c}$ Raul Angelo Balbinot ${ }^{a, c}$ Jonathan Soldera ${ }^{a, b}$ \\ ${ }^{a}$ Faculty of Medicine, Universidade de Caxias do Sul, Caxias do Sul, Brazil; ${ }^{\text {b Universidade }}$ \\ Federal de Ciências da Saúde de Porto Alegre, Porto Alegre, Brazili ${ }^{C}$ Clinical \\ Gastroenterology, Universidade de São Paulo, São Paulo, Brazil
}

\section{Keywords}

Hepatocellular carcinoma · Brain metastasis · Intraparenchymal hemorrhage

\begin{abstract}
Although extrahepatic metastases from hepatocellular carcinoma (HCC) are present in only $5-15 \%$ of cases, they are certainly factors associated with poor prognosis. The main sites include lung, lymph nodes, bones, and adrenal glands, in descending order. Metastasis in the central nervous system is extremely rare, and the incidences vary from 0.6 to $1.7 \%$. We report a case of a 54-year-old man previously diagnosed with alcohol-induced cirrhosis of the liver and HCC. The patient was admitted presenting progressive left hemiparesis and headache which started 2 days earlier, with no history of cranioencephalic trauma. After admission, cranial computed tomography revealed an intraparenchymal hemorrhage area with surrounding edema in the right frontal lobe. An angioresonance requested showed a large extra-axial mass lesion located in the right frontal region with well-defined contours and predominantly hypointense signal on T2 sequence. At first, the radiological findings suggested meningioma as the first diagnostic hypothesis. However, the patient underwent surgery. The tumor was completely removed, and the morphological and immunohistochemical findings
\end{abstract}


were consistent with metastatic hepatocarcinoma associated with meningioma. In postoperative care, the patient did not recover from the left hemiparesis and manifested Broca's aphasia. He had a survival time of 24 weeks, presenting acute liver failure as his cause of death. There is a lack of evidence supporting a specific management of patients with brain metastasis from HCC. Furthermore, there are no studies that evaluate different modalities of therapeutics in brain metastasis of HCC due to the rarity of this condition. Therefore, management must be individualized depending on probable prognostic factors in these patients.

(C) 2017 The Author(s)

Published by S. Karger AG, Basel

\section{Introduction}

Hepatocellular carcinoma (HCC) is one of the most common malignancies worldwide. It is responsible annually for 250,000 to 1 million deaths globally [1-4]. It is the fifth most frequent cancer in men and the seventh in women [5]. The incidence varies widely, not only among continents, but also among different locations within the same country. This is due to the fact that environmental risk factors and hepatitis virus exposures vary within different geographic regions. High-incidence regions are generally those endemic for hepatitis B virus (HBV), such as sub-Saharan Africa and Southeast Asia [6]. In contrast, North and South America, Australia, and most of Europe are areas of a low incidence of HCC, with about 3 cases per 100,000 per year.

However, in the past few decades, the HCC incidence changed not only in the highincidence regions, where it has been decreasing, but also in the low-incidence areas, where it has been increasing $[8,9]$. It is proposed that the increasing incidence of HCC in countries such as the United States, Canada, United Kingdom, and Australia is associated mainly with the peak of the incidence of cirrhosis due to chronic hepatitis $C$ and with the increasing prevalence of nonalcoholic fatty liver disease [8-11]. It is probable that the decreasing incidence of HCC in high-incidence areas is due to HBV vaccination and treatment and the increase of the availability of screening programs in patients with chronic liver disease.

Brazil has a low incidence of HCC - 3.5 new cases annually for men and 3.7 for women per 100,000. Currently, there is little evidence regarding the epidemiology of HCC in Brazil. Nevertheless, the data available suggest that the different distribution of HCC prevalence is due to the heterogeneous prevalence of HBV in Brazil [12].

We report the case of a patient with alcohol-induced cirrhosis and HCC, in which progression developed an intraparenchymal hemorrhage due to brain metastasis from the HCC.

\section{Case Report}

A 54-year-old male with cirrhosis due to chronic alcoholic liver disease presented to our hospital with progressive left hemiparesis and headache which started 2 days earlier, with no history of head trauma. A previous diagnosis of HCC was made in August 2015 with a triple-phase CT abdominal scan, which showed a solid mass in the liver, hypodense, measuring $5.2 \times 4.7 \mathrm{~cm}$ in the axial plane in the left lobe, with slightly heterogeneous enhancement 


\section{Case Reports in Gastroenterology} \begin{tabular}{l|l}
\hline Case Rep Gastroenterol 2017;11:516-525 \\
\hline DOI: $10.1159 / 000479221$ & $\begin{array}{l}\text { (c 2017 The Author(s). Published by S. Karger AG, Basel } \\
\text { www.karger.com/crg }\end{array}$ \\
\hline
\end{tabular}

Sartori Balbinot et al.: Intraparenchymal Hemorrhage due to Brain Metastasis of Hepatocellular Carcinoma

by means of contrast in the arterial phase, and slightly hypodense in the excretory phase (Fig. 1). The plan was to perform a transarterial chemoembolization, but the patient was lost to follow-up after the diagnosis. The patient was using propranolol, furosemide and lansoprazole. Also, he was being treated for systemic hypertension with enalapril and amlodipine, for type 2 diabetes mellitus with metformin and for dyslipidemia with simvastatin.

On physical examination, the patient was alert, oriented, and cooperative. Pupils were equal, round, reactive to light and accommodation. Glasgow Coma Scale was 15. He presented loss of strength in his left upper and lower members, but worse distally graded as II/IV. There were no sensory deficits. The Babinski reflex was positive in the left member. Other physical observations were unremarkable. Laboratory values were: glucose $160 \mathrm{mg} / \mathrm{dL}$, sodium $139 \mathrm{mmol} / \mathrm{L}$, potassium $3.9 \mathrm{mmol} / \mathrm{L}$, international normalized ratio 1.2, activated partial thromboplastin time $24.5 \mathrm{~s}$, hemoglobin $13.6 \mathrm{~g} / \mathrm{dL}$, leukocyte count $6,680 / \mathrm{mm}^{3}$, platelet count $103,000 / \mathrm{mm}^{3}$, total bilirubin $1.7 \mathrm{mg} / \mathrm{dL}$, serum albumin $3.5 \mathrm{~g} / \mathrm{dL}$, creatinine $0.6 \mathrm{mg} / \mathrm{dL}$; Child-Pugh score A, and MELD-Na score 11.2 .

A cranial CT scan demonstrated an intraparenchymal hemorrhage area in the high convexity of the right frontal lobe, associated with surrounding edema, with about $4.7 \mathrm{~cm}$ of determining mass effect, with slight deviation of the midline. There was no evidence of head injury (Fig. 2).

The patient underwent a cranial angioresonance for presurgical mapping, which demonstrated a large extra-axial mass lesion located in the skull of the frontal region, measuring about $4.5 \times 4.2 \times 3.3 \mathrm{~cm}$ well-defined contours of diameters, with predominantly hypointense signal on $\mathrm{T} 2$ sequence. The injury had some small cystic areas in between and intense enhancement by means of intravenous contrast, with vasogenic edema surrounding brain parenchyma, with small areas of bleeding (Fig. 3).

The patient underwent a decompressive craniotomy and the tumor was completely removed. There were no intercurrences during surgery. Histopathological examination revealed that morphological (Fig. 4) and immunohistochemical (Table 1) findings were consistent with metastatic hepatocarcinoma associated with meningioma.

There were no complications during surgery and postoperative care. Nevertheless, the patient did not recover from the left hemiparesis and manifested Broca's aphasia, which deteriorated progressively during the following months. After surgery, the patient received neoadjuvant radiation therapy in order to prevent cerebral metastatic relapses. There was no indication for HCC or liver therapies. From this management, the patient had a survival time of 24 weeks, presenting acute liver failure as his cause of death.

\section{Discussion}

The vast majority of HCC cases occur in patients with liver cirrhosis. At diagnosis, the clinical features are variable. Patients can be asymptomatic or only present the manifestations of decompensated liver cirrhosis [13]. Extrahepatic spread is uncommon at diagnosis, ranging from 5 to $15 \%$ of the cases [14-16]. During disease progression, these lesions have been reported to occur in approximately $13.5-42 \%$ of HCC patients [17-19]. The most common sites for metastasis are lung, intra-abdominal lymph nodes, bones, and adrenal glands. Central nervous system metastasis is extremely rare. Hence there is a lack of retrospective 


\section{Case Reports in \\ Gastroenterology}

Case Rep Gastroenterol 2017;11:516-525

(c) 2017 The Author(s). Published by S. Karger AG, Basel www.karger.com/crg

Sartori Balbinot et al.: Intraparenchymal Hemorrhage due to Brain Metastasis of Hepatocellular Carcinoma

studies assessing this incidence. Kim et al. [20] reported an incidence of $0.6 \%$ [21], while Friedman [22] reported an incidence varying from 0.3 to $1.7 \%$.

In adults, the most frequent intracranial malignancies are metastasis. However, some data suggest that intracranial hemorrhage due to metastasis from distant primary cancers occurs only in between 0.9 and $11 \%$ [23].

Brain metastasis from HCC is rare. The improvement in screening and therapeutic modalities increased the survival of patients with HCC. It is expected, therefore, that the incidence of HCC with brain metastasis will increase [24]. Besides, there are no guidelines for the management of these patients, but some advanced therapeutic techniques have shown an improvement of the median survival time, such as surgical resection, local ablation, transarterial chemoembolization, and chemotherapeutic agents [24]. Nevertheless, there is a lack of studies that evaluate the survival rates of patients treated with these different therapeutic modalities.

In the natural history of the HCC, there is first a contiguous invasion of portal and hepatic veins. Usually, regional lymph nodes are affected in the sequence [25]. Afterwards, hematogenous spread tends to occur in lungs, bones, and adrenal glands [26-28]. Since the survival rates of HCC have been increasing, the central nervous system could be considered as the next metastatic site of HCC, albeit very rare. Besides, metastasis not only from HCC but also from other carcinomas commonly occurs in the middle cerebral artery territory [29]. Spontaneous intracerebral hemorrhages due to HCC metastasis are also extremely rare. There are 8 cases of spontaneous epidural hematoma [30-38] and 1 case of subdural hematoma [29] due to brain metastasis of HCC reported in the literature to this date.

Han et al. [21] retrospectively reviewed 32 cases of HCC with brain metastasis regarding clinical and radiological findings. These patients were selected from a group of 5,015 patients diagnosed with HCC, with an incidence of $0.65 \%$. Median survival time after the diagnosis of brain metastasis was 10.4 weeks. Most cases (97\%) are symptomatic. The most common findings were headache, weakness, and mental status changes. Those findings are probably associated with a high incidence of intratumoral hemorrhage. Child-Pugh score A, absence of intratumoral hemorrhage, recursive partitioning analysis class I or II and surgical resection were associated with higher survival rates.

Another relevant finding in this patient is the association between the brain metastasis from HCC and a meningioma, which is another rare situation, confirmed by the histopathological examination. Meningioma is the most frequent primary central nervous system tumor, which is responsible for about one-third of all primary brain and spinal tumors [38]. However, there are no cases reported in the literature with the association of central nervous system tumors presented in this patient.

Despite the intratumoral hemorrhage, in this case the patient's Child-Pugh score was A, which could be associated with an increase in survival. Besides, during the postoperative care, the patient did not present any complications.

\section{Conclusion}

Early recognition is certainly one of the factors related to higher survival in patients with brain metastasis from HCC, since about $90 \%$ of cases are symptomatic [15]. Besides, in 
a considerable group of patients there are focal neurological deficits. Although brain metastasis from HCC is not the first hypothesis to be considered in this case, it should certainly be included as a differential diagnosis, especially with the increase in survival time in patients with HCC. There is lack of evidence not only for identifying other prognostic factors, but also for defining the appropriate treatment of these patients. Therapeutics must be individualized, considering probable prognostic factors in the decision of the management to this date.

\section{Statement of Ethics}

The patient data in the reported case are blinded so the patient cannot be identified.

\section{Disclosure Statement}

The authors have no conflict of interest regarding the topic of this paper.

\section{References}

Munoz N, Bosch X: Epidemiology of hepatocellular carcinoma; in Okuda K, Ishak KG (eds): Neoplasms of the Liver. Tokyo, Springer,1989, p 3.

2 Muir C, Waterhouse J, Mack T, et al: Cancer incidence in five continents. Lyon, International Agency for Research on Cancer, 1987, vol 5 (IARC Publications, No 88).

3 Bosch FX, Munoz N: Hepatocellular carcinoma in the world: epidemiologic questions; in Tabor E, DiBisceglie AM, Purcell RH (eds): Etiology, Pathology and Treatment of Hepatocellular Carcinoma in America. Advances in Applied Technology Series. Gulf Pulishing, Houston, 1991, p 35.

4 Okuda K: Epidemiology of primary liver cancer; in Tobe T (ed): Primary Liver Cancer in Japan. Tokyo, Springer, 1992, p 3.

Jemal A, Bray F, Center MM, et al: Global cancer statistics. CA Cancer J Clin 2011;61:69.

Bosch FX, Ribes J, Cléries R, Díaz M: Epidemiology of hepatocellular carcinoma. Clin Liver Dis 2005;9:191-211. Sherman M: Epidemiology of hepatocellular carcinoma. Oncology 2010;78(suppl 1):7-10. Davila JA, Morgan RO, Shaib Y, et al: Hepatitis C infection and the increasing incidence of hepatocellular carcinoma: a population-based study. Gastroenterology 2004;127:1372.

$\checkmark 9$ El-Serag HB, Davila JA, Petersen NJ, McGlynn KA: The continuing increase in the incidence of hepatocellular carcinoma in the United States: an update. Ann Intern Med 2003;139:817. El-Serag HB: Hepatocelular carcinoma: recent trends in the United States. Gastroenterology 2004;127:S27-S34.

11 Cancer Research UK: Liver cancer incidence statistics (accessed October 18, 2015). http://info.cancerresearchuk.org/cancerstats/types/liver/incidence/?a = 5441.

12 Carrilho FJ, et al: Clinical and epidemiological aspects of hepatocellular carcinoma in Brazil. Clinics (Sao Paulo) 2010;65:1285-1290.

13 Choi HJ, Cho BC, Sohn JH, et al: Brain metastases from hepatocellular carcinoma: prognostic factors and outcome: brain metastasis from HCC. J Neurooncol 2009;91:307. Kew MC, Dos Santos HA, Sherlock S: Diagnosis of primary cancer of the liver. Br Med J 1971;4:408. Shao YY, Lu LC, Cheng AL, Hsu CH: Increasing incidence of brain metastasis in patients with advanced hepatocellular carcinoma in the era of antiangiogenic targeted therapy. Oncologist 2011;16:82. Yoo DJ, Kim KM, Jin YJ, et al: Clinical outcome of 251 patients with extrahepatic metastasis at initial diagnosis of hepatocellular carcinoma: does transarterial chemoembolization improve survival in these patients? J Gastroenterol Hepatol 2011;26:145. 


\section{Case Reports in Gastroenterology}

Sartori Balbinot et al.: Intraparenchymal Hemorrhage due to Brain Metastasis of Hepatocellular Carcinoma

17 Katyal S, Oliver JH 3rd, Peterson MS, et al: Extrahepatic metastases of hepatocellular carcinoma. Radiology 2000;216:698.

18 Si MS, Amersi F, Golish SR, Ortiz JA, Zaky J, Finklestein D, Busuttil RW, Imagawa DK: Prevalence of metastases in hepatocellular carcinoma: risk factors and impact on survival. Am Surg 2003;69:879888.

19 Shuto T, Hirohashi K, Kubo S, Tanaka H, Yamamoto T, Higaki I, Takemura S, Kinoshita H: Treatment of adrenal metastases after hepatic resection of a hepatocellular carcinoma. Dig Surg 2001;18:294-297. Kim M, Na DL, Park SH, Jeon BS, Roh JK: Nervous system involvement by metastatic hepatocellular carcinoma. J Neurooncol 1998;36:85-90.

Han M-S, Moon K-S, Lee K-H, et al: Brain metastasis from hepatocellular carcinoma: the role of surgery as a prognostic factor. BMC Cancer 2013;13:567. Friedman HD: Hepatocellular carcinoma with central nervous system metastasis: a case report and literature review. Med Pediatr Oncol 1991;19:139-144.

23 Wakisaka S, Tashiro M, Nakano S, Kita T, Kisanuki H, Kinoshita K: Intracranial and orbital metastasis of hepatocellular carcinoma: report of two cases. Neurosurgery 1990;26:863-866.

24 Rahbari NN, Mehrabi A, Mollberg NM, Muller SA, Koch M, Buchler MW, Weitz J: Hepatocellular carcinoma: current management and perspectives for the future. Ann Surg 2011;253:453-469. Jang SY, Kim CH, et al: Concomitant subdural hemorrhage and intracerebral hemorrhage due to brain metastasis of the hepatocellular carcinoma. Brain Tumor Res Treat 2015;3:48-51. Lee JP, Lee ST: Hepatocellular carcinoma presenting as intracranial metastasis. Surg Neurol 1988;30:316-320.

-27 Loo KT, Tsui WM, Chung KH, Ho LC, Tang SK, Tse CH: Hepatocellular carcinoma metastasizing to the brain and orbit: report of three cases. Pathology 1994;26:119-122.

-28 Wakai S, Yamakawa K, Manaka S, Takakura K: Spontaneous intracranial hemorrhage caused by brain tumor: its incidence and clinical significance. Neurosurgery 1982;10:437-444.

29 Yang WT, Yeo W, Leung SF, Chan YL, Johnson PJ, Metreweli C: MRI and CT of metastatic hepatocellular carcinoma causing spinal cord compression. Clin Radiol 1997;52:755-760. Tanaka Y, Kawaguchi J, Hayashi H, et al: Nontraumatic subdural hematoma secondary to dural metastasis of hepatocellular carcinoma: case report and review of the literature. Jpn J Stroke 2004;26:382-386.

31 Endo M, Hamano M, Watanabe K, Wakai S: Combined chronic subdural and acute epidural hematoma secondary to metastatic hepatocellular cancer: case report (in Japanese). No Shinkei Geka 1999;27:331-334.

32 Hayashi K, Matsuo T, Kurihara M, Daikoku M, Kitange G, Shibata S: Skull metastasis of hepatocellular carcinoma associated with acute epidural hematoma: a case report. Surg Neurol 2000;53:379-382. Kim BG, Yoon SM, Bae HG, Yun IG: Spontaneous intracranial epidural hematoma originating from dural metastasis of hepatocellular carcinoma. J Korean Neurosurg Soc 2010;48:166-169. Lee KW, Chung DS, Huh PW, Hong YK, Rha HK, Kang JK: Intracranial metastasis of hepatocellular carcinoma associated with epidural hematoma: a case report. J Korean Neurosurg Soc 1996;25:17381742. epidural hematoma: case report. Neurosurgery 2001;49:447-449.

-36 Nakagawa Y, Yoshino E, Suzuki K, Tatebe A, Andachi H: Spontaneous epidural hematoma from a hepatocellular carcinoma metastasis to the skull - case report. Neurol Med Chir (Tokyo) 1992;32:300302.

-37 Nakao N, Kubo K, Moriwaki H: Cranial metastasis of hepatocellular carcinoma associated with chronic epidural hematoma - case report. Neurol Med Chir (Tokyo) 1992;32:100-103.

-38 Woo KM, Kim BC, Cho KT, Kim EJ: Spontaneous epidural hematoma from skull base metastasis of hepatocellular carcinoma. J Korean Neurosurg Soc 2010;47:461-463.

39 Chou R, Cuevas C, Fu R, et al: Imaging techniques for the diagnosis of hepatocellular carcinoma: a systematic review and meta-analysis. Ann Intern Med 2015;162:697. 


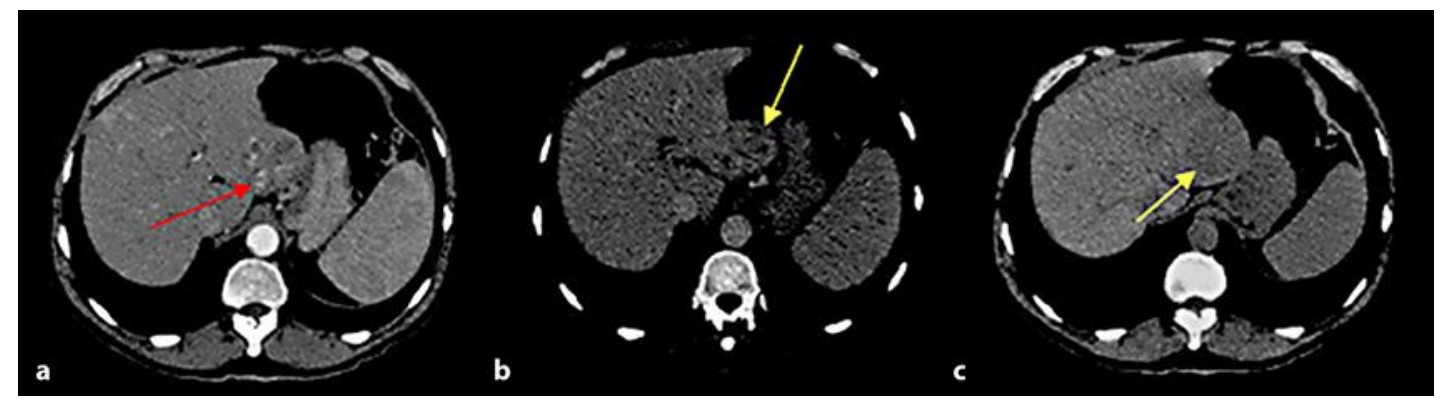

Fig. 1. Triple-phase CT scan. a Arterial phase of contrast enhancement showing neovascularity (red arrow) in a low-density hepatic mass in the left lobe. b, c Portal and excretory phases are shown, respectively; there is a hypodensity (yellow arrow) in the same topography. These findings are commonly referred to by radiologists as "arterial enhancement with washout" and they have high accuracy in the diagnosis of HCC (sensitivity of $83 \%$ and specificity of $91 \%$ [39]).

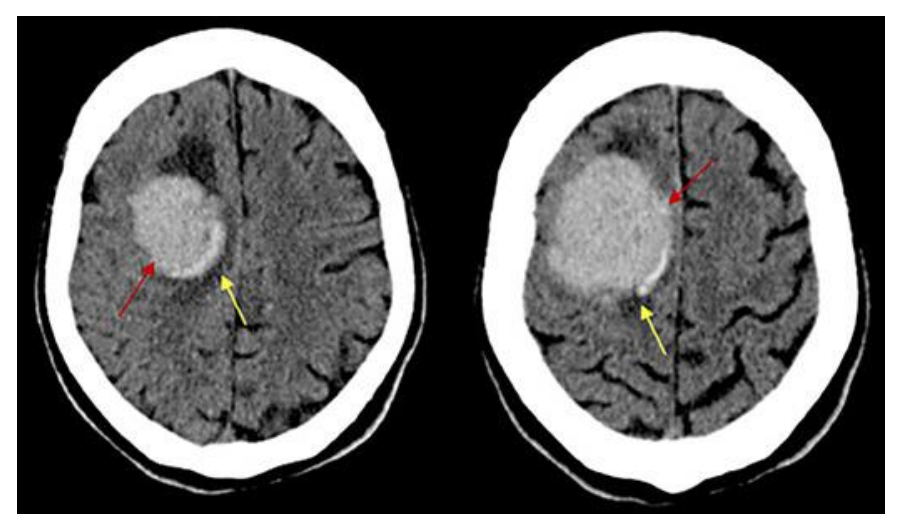

Fig. 2. CT scan of the brain demonstrating an intraparenchymal hemorrhage area (red arrow) in the right frontal lobe. There is a surrounding edema (yellow arrow) associated with the lesion. 


\section{Case Reports in Gastroenterology}

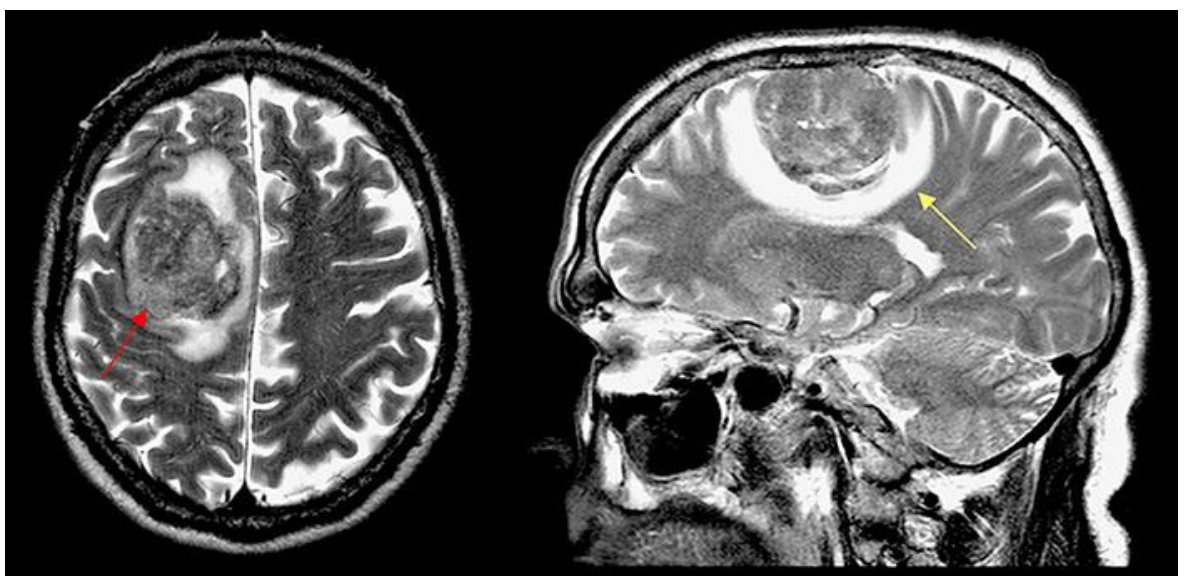

Fig. 3. Cranial angioresonance demonstrating a massive lesion located in the skull in the frontal region (red arrow), $4.5 \times 4.2 \times 3.3 \mathrm{~cm}$ in size, that presents a predominantly hypointense signal on T2 sequence. Vasogenic edema surrounding (yellow arrow) the brain parenchyma with areas of hemorrhage can be seen. 


\section{Case Reports in \\ Gastroenterology}

\begin{tabular}{l|l}
\hline Case Rep Gastroenterol 2017;11:516-525 \\
\hline DOI: 10.1159/000479221 & $\begin{array}{l}\text { (c 2017 The Author(s). Published by S. Karger AG, Basel } \\
\text { www.karger.com/crg }\end{array}$
\end{tabular}

Sartori Balbinot et al.: Intraparenchymal Hemorrhage due to Brain Metastasis of Hepatocellular Carcinoma
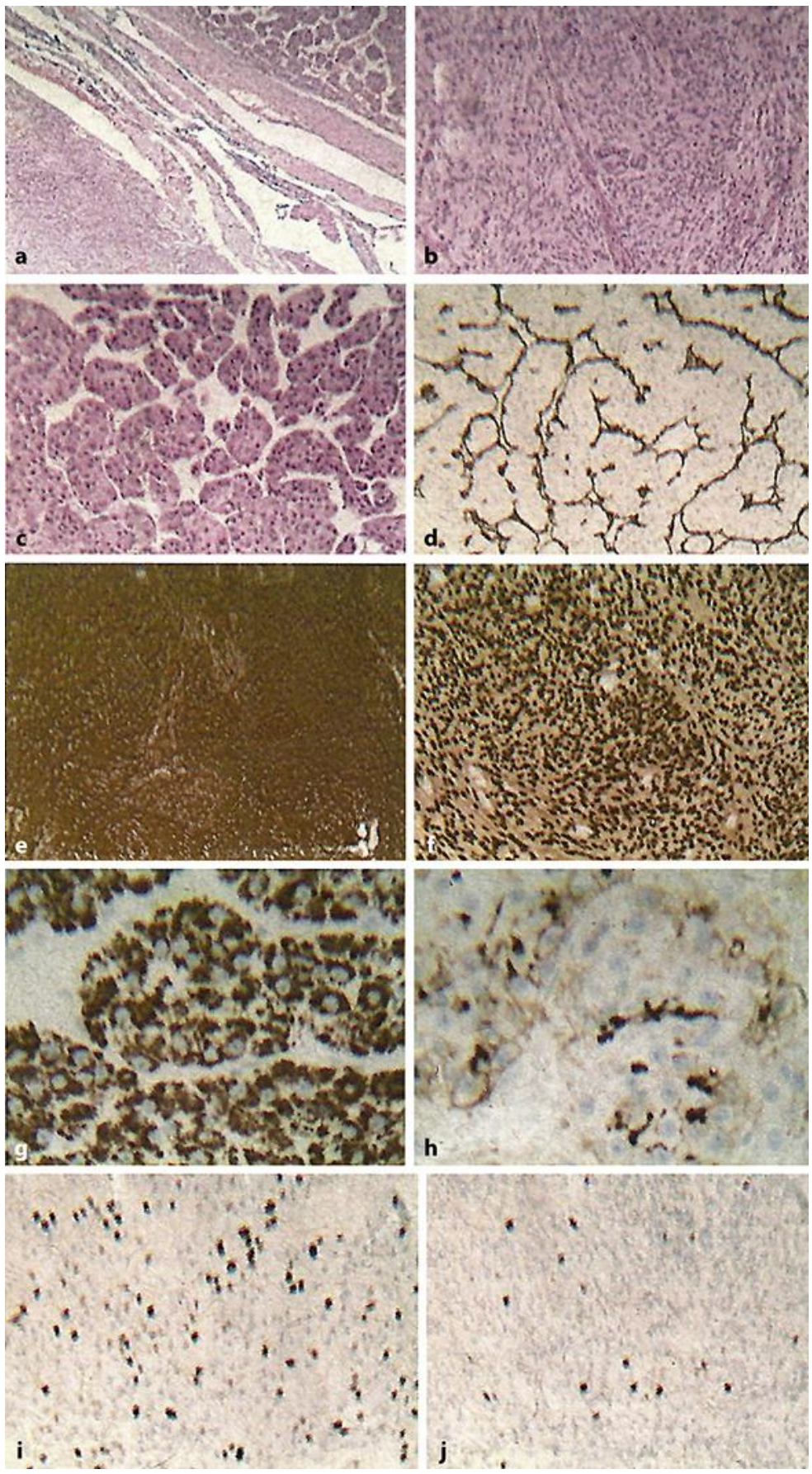

Fig. 4. Microscopic findings. a Transition. HE. $\times 400$. b Meningioma. HE. $\times 400$. $\mathbf{c}$ HCC. HE. $\times 400$. $d$ HCC. Vimentin. $\times 400$. e Meningioma. Vimentin. $\times 400$. $\mathrm{f}$ Meningioma. Progesterone receptor. $\times 400$. g HCC. HepPar-1. ×400. h HCC. CD10. ×400. i HCC. Ki67. ×400. j Meningioma. Ki67. ×400. 
Table 1. Immunohistochemistry panel

\begin{tabular}{ll}
\hline Antibody & Result \\
\hline Cytokeratin 7 (OV-TL 12/30) & Negative \\
\hline Cytokeratin 20 (Ks20.8) & Negative \\
\hline Ki67 (MIB-1) & $\begin{array}{l}\text { Positive in 5\% of meningioma cells and 25\% of HCC } \\
\text { cells }\end{array}$ \\
\hline $\begin{array}{l}\text { Cytokeratin 18 (DC-10) } \\
\text { CDX-2: intestine-specific transcription } \\
\text { factor (DAK CDX-2) }\end{array}$ & Positive in HCC \\
\hline $\begin{array}{l}\text { Vimentin (V9) } \\
\text { TTF-1: thyroid transcription factor-1 } \\
\text { (8G7G3/1) }\end{array}$ & Pegative \\
\hline Hepatocyte: Hep Par-1 (OCH1E5) & Positive in HCC (cytoplasmic labeling) \\
\hline $\begin{array}{l}\text { Progesterone receptor (PgR636) } \\
\text { Chromogranin A (DAK-A3) }\end{array}$ & Positive in HCC \\
\hline $\begin{array}{l}\text { CD10 (56C6) } \\
\text { HCC, hepatocellular carcinoma. }\end{array}$ & Positive in meningioma \\
\hline
\end{tabular}

